\title{
Erratum: Alterations Functional Connectivity in Temporal Lobe Epilepsy and Their Relationships With Cognitive Function: A Longitudinal Resting-State fMRI Study
}

\author{
Frontiers Production Office* \\ Frontiers Media SA, Lausanne, Switzerland
}

Keywords: temporal lobe epilepsy, functional magnetic resonance imaging, dorsolateral prefrontal cortex, longitudinal study, cognitive function

Frontiers Editorial Office, Frontiers Media SA, Switzerland

*Correspondence:

Frontiers Production Office production.office@frontiersin.org

Specialty section:

This article was submitted to

Epilepsy,

a section of the journal

Frontiers in Neurology

Received: 05 October 2020 Accepted: 06 October 2020 Published: 27 October 2020

Citation:

Frontiers Production Office (2020)

Erratum: Alterations Functional

Connectivity in Temporal Lobe Epilepsy and Their Relationships With

Cognitive Function: A Longitudinal Resting-State fMRI Study.

Front. Neurol. 11:614081.

doi: 10.3389/fneur.2020.614081

\section{An Erratum on}

Alterations Functional Connectivity in Temporal Lobe Epilepsy and Their Relationships With Cognitive Function: A Longitudinal Resting-State fMRI Study

by Qin, L., Jiang, W., Zheng, J., Zhou, X., Zhang, Z., and Liu, J. (2020). Front. Neurol. 11:625. doi: 10.3389/fneur.2020.00625

Due to a production error, incorrect affiliations were provided for Lu Qin and Wenyu Jiang. Instead of "Department of Neurology, The First Affiliated Hospital of Guangxi Medical University, Nanning, China," it should be "Department of Neurology, Liuzhou Workers' Hospital/The Fourth Affiliated Hospital of Guangxi Medical University, Liuzhou, China” for Lu Qin, and "Department of Neurology, Jiangbin Hospital of Guangxi Zhuang Autonomous Region, Nanning, China” for Wenyu Jiang.

The publisher apologizes for this mistake. The original article has been updated.

Copyright $\odot 2020$ Frontiers Production Office. This is an open-access article distributed under the terms of the Creative Commons Attribution License (CC BY). The use, distribution or reproduction in other forums is permitted, provided the original author(s) and the copyright owner(s) are credited and that the original publication in this journal is cited, in accordance with accepted academic practice. No use, distribution or reproduction is permitted which does not comply with these terms. 